\title{
Estimation of Accumulated Degree Day Value of Six Landmarks within the Pupal Stage of Lucilia sericata
}

\author{
Annalisa Grisendi ${ }^{1}$, Francesco Defilippo ${ }^{2}$, Fabio Gatti ${ }^{1}$, Michele Dottori ${ }^{2}$ and Paolo Bonilauri ${ }^{2}$ \\ 1. University of Parma, Via Farini 90, Parma 43121, Italy \\ 2. Istituto Zooprofilattico Lombardia e Emilia-Romagna, Via Pitagora 2, Reggio Emilia 42124, Italy
}

Received: July 24, 2015 / Accepted: July 26, 2015 / Published: July 30, 2015.

\begin{abstract}
The present paper investigates the pupal development times of Lucilia sericata which were studied in the laboratory at six different constant temperatures $\left(20,22,24,26,28{ }^{\circ} \mathrm{C}\right.$ each $\left.\pm 1{ }^{\circ} \mathrm{C}\right)$. Lower thresholds $\left(\mathrm{t}_{\mathrm{L}}\right)$ for development were estimated from the linear regression of the developmental rates on each temperature. These data have made it possible to calculate the ADD (Accumulated Degree-Days) necessary for L. sericata to complete the larval stage and to achieve adult emergence. The minimal duration of development from oviposition to adult emergence was found to be inversely related to temperature. Additionally, six landmarks in pupal development are showed and for each of the landmarks the ADD value was calculated for every rearing temperature involved. These data assist in calculating the duration of the pupal stage based on morphological characteristics and would be of great value for future forensic entomological casework.
\end{abstract}

Key words: Forensic science, forensic entomology, Lucilia sericata, pupal landmarks, accumulated degree day, post-mortem interval.

\section{Introduction}

Forensic entomology is the name given to the study of insects (or even other arthropods) that form part of the evidence in legal cases [1], but it is mainly associated with death enquiries.

Every death investigation relies on an accurate estimation of the time of death or the period since death, termed as the PMI (post mortem interval).

The ages of insect immature stages found on a dead body can provide evidence for the estimation of a minimum PMI ranging from 1 day up to more than 1 month, depending on the insect species involved and the climatic conditions at the death scene.

Blowflies are typically the first colonizers, attracted to the carrion by the odour produced during decomposition [2-4], even over large distances [5, 6].

Corresponding author: Francesco Defilippo, M.S., research fields: forensic and veterinary entomology. E-mail: francesco.defilippo@izsler.it.
Calliphoridae, among the first colonizers of cadavers, may serve as a biological clock in measuring the time of death for two or more weeks. These insects include species of Calliphora, Protophormia and Lucilia [7].

Because the rate of development of the immature stages is a function of the ambient temperature, the age of specimens is positively correlated with the summed thermal input they accumulated during growth [8-12]. The standard technique used to estimate the rate of development of insects over a period of time with temperature compensation is termed ADH (accumulated degree hours) or ADD (accumulated degree days), which are a summation of temperature $\left({ }^{\circ} \mathrm{C}\right)$ above the LDT (lower development threshold) multiplied by time (hours or days). The LDT is the temperature value below which insect development stops and it is species-specific and can vary between life stages.

Since it is more difficult to determine a pupa's age than that of a larva, because the morphological 
changes are often not visible during the development of the pupa and the pupal stage can last up to $50 \%$ of the whole juvenile development the study of morphological changes during the pupal stage of $L$. sericata can also be employed to estimate the age of insect and thus for determination of death chronology especially when pupae represent the oldest specimens present at a crime scene or even the only source of entomological evidence available.

Therefore complementary to the present study, a detailed study involving the use of landmarks to fix different pupal stages [13] to better define its pupal developmental duration under different constant temperature regimes, was undertaken and for each landmarks was calculated the ADD value. The present study reports on a series of laboratory experiments that explore the effects of constant temperatures on the development of the species Lucilia sericata with particular reference to ADD estimation and the observation of six landmarks to fix different pupal phases.

\section{Materials and Methods}

Adults of $L$. sericata were initially collected in the surroundings of the Reggio Emilia division of IZSLER (Istituto Zooprofilattico Sperimentale della Lombardia e Emilia-Romagna) during the fly-active period of the years 2013-2014 (North of Italy, Lat. $44^{\circ} 42^{\prime} 32.34^{\prime \prime}$ N, Long. 10³7'36.66" E). Adults were identified using the morphological characters described by Smith [14] and larvae were reared according to the procedures described by Richards et al. in 2009 [15] and Ames and Turner in 2003 [8].

\subsection{Insect Rearing}

Fresh pig's muscle (diaphragm) was provided as protein source a few days before eggs requirement. Then the oviposition time was recorded, and muscle and eggs were removed and transferred into plastic jars $(10 \mathrm{~cm} \times 15 \mathrm{~cm} \times 22 \mathrm{~cm})$ covered with a gauze-net. The bottom of the jars was covered with 3 $\mathrm{cm}$ thick sawdust, to provide a dry place for pupation.

The jars were then placed into a precision environmental chamber (SENECO ${ }^{\circledR}$ Mod. ClimaCell $404)$ at one of six desired temperature regimes (20, 22, 24, 26, $28{ }^{\circ} \mathrm{C}$ each $\pm 1{ }^{\circ} \mathrm{C}$, respectively), with a relative humidity set to $70 \%$. This procedure was repeated 3 times for each temperature regime $(n=3)$ and approximately 150 eggs were used in each replicate.

Larvae were fed muscle which was regularly changed to ensure food was in excess and therefore larval competition was avoided.

Twice a day, the authors recorded the mean temperature within the centre of the actively feeding maggots using a digital thermometer $\left( \pm 0.6^{\circ} \mathrm{C}\right)$. Rearing conditions were never modified.

\subsection{Landmarks Division}

Following the removal of pupal case, five pupae were examined with stereo-microscope (Nikon SMZ 1500 ) every $4 \mathrm{~h}$ during metamorphosis to observe and stage the flies.

Based on visible external characteristics and landmarks described by Sivasubramanian and Biagi [13] for Sarcophaga bullata and Defilippo [16] for Calliphora vicina, the pupal period of L. sericata was divided into six stages: Cryptocephalic pupa [S1] (the head is still invaginated); Phanerocephalic pupa [S2] (complete eversion of the head and thoracic appendages); Pharate adult [S3] (visible segmentation in the thorax, legs and abdomen); Yellow eyed [S4] (beginning of eye pigmentation and ocelli are visible); Tanned chaetae [S5] (all the bristles, both macro- and microchaetae, are fully tanned, except a few at the distal margin of the leg and abdominal segments, which are still brownish) and Tanned legs [S6] (all the bristles, legs and wings are fully tanned) (Figs. 1-9).

To facilitate puparium removal and improve character visibility, pupae was immerse into sodium alginate gel (E401 1\%) before the observation [17]. 


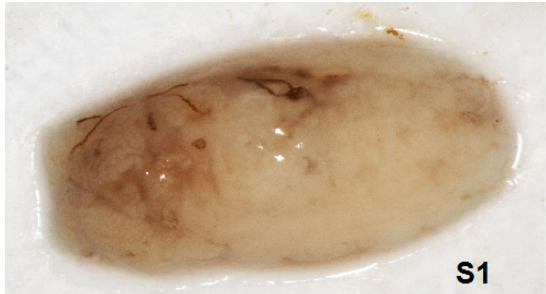

Fig. 1 Dorsal view of Cryptocephalic pupa [S1] with uneverted head.

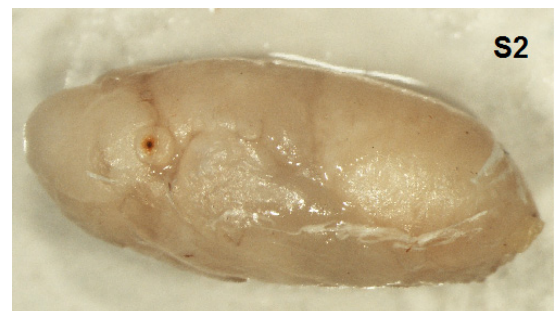

Fig. 2 Lateral view of Phanerocephalic pupa [S2] showing fully everted head and thoracic appendages.

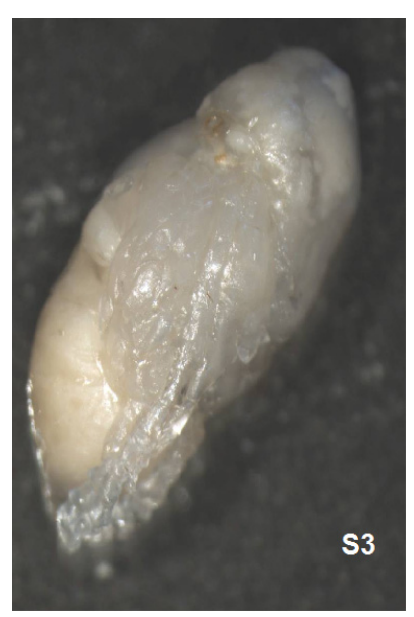

Fig. 3 Lateral view of Pharate adult landmark [S3].

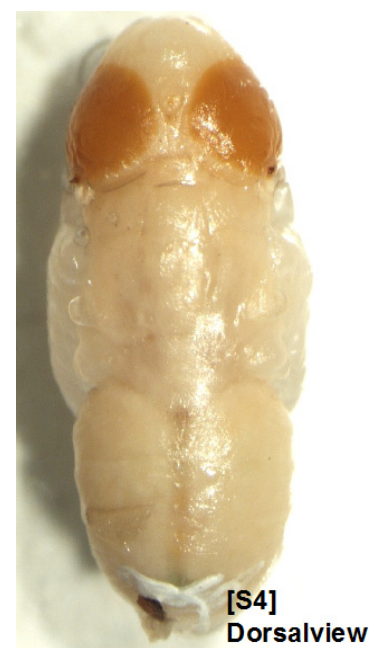

Fig. 4 Dorsal view and Ventral view of Yellow eyed landmark [S4].

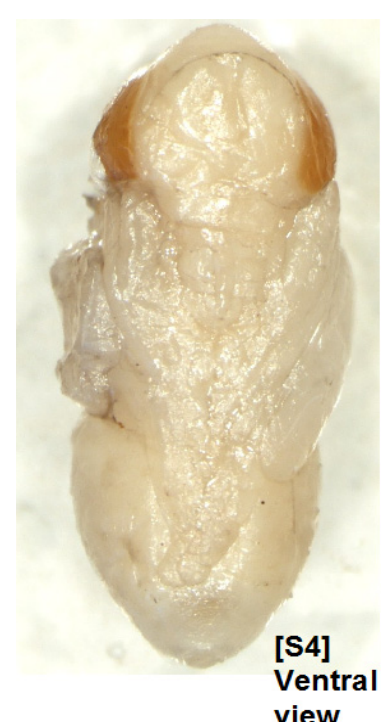

Fig. 5 Dorsal view and Ventral view of Yellow eyed landmark [S4].

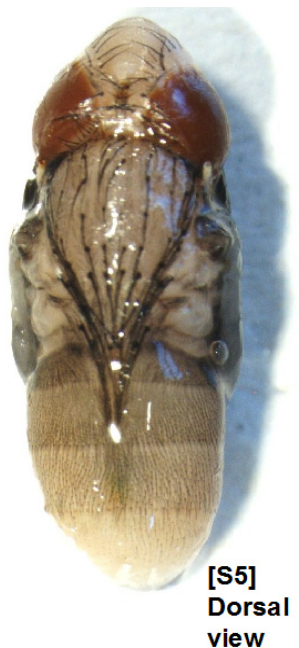

Fig. 6 Dorsal view and Ventral view of Tanned chaetae [S5] with fully tanned chaetae.

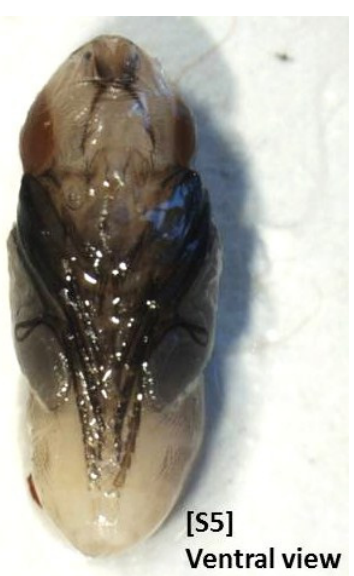

Fig. 7 Dorsal view and Ventral view of Tanned chaetae [S5] with fully tanned chaetae. 


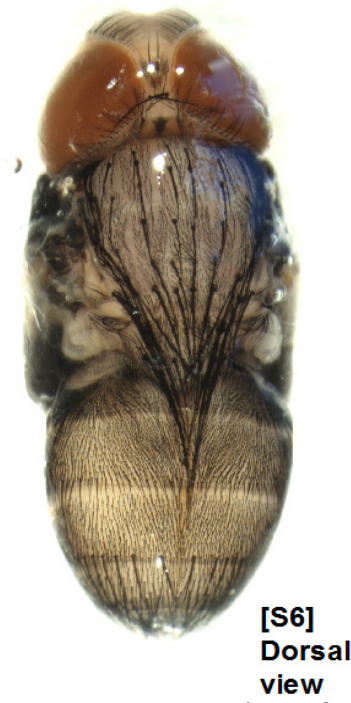

Fig. 8 Dorsal view and Ventral view of Tanned legs [S6] showing legs and wings fully tanned.

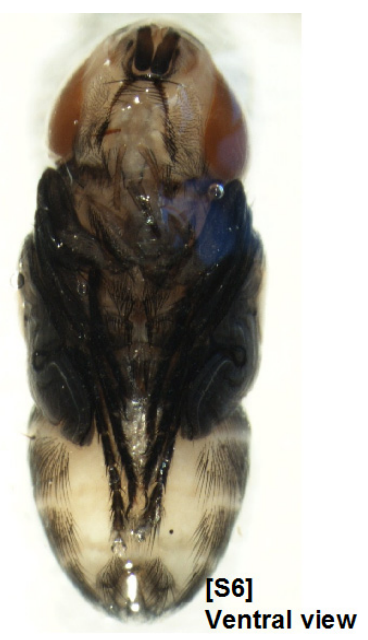

Fig. 9 Dorsal view and Ventral view of Tanned legs [S6] showing legs and wings fully tanned.

\subsection{Lower Developmental Threshold and ADD}

The ADD for the period egg-eclosion was calculated for each of the six constant temperature regimes to obtain the overall $\mathrm{ADD}$ (mean \pm S.D.), according to the following formula:

$$
\mathrm{ADD}=\mathrm{d}\left(\mathrm{t}-\mathrm{t}_{\mathrm{L}}\right)
$$

where $\mathrm{d}$ (days) is the developmental time, $\mathrm{t}$ is the rearing temperature $\left({ }^{\circ} \mathrm{C}\right)$, and $t_{L}$ is the lower developmental threshold temperature $\left({ }^{\circ} \mathrm{C}\right)$.

Lower thresholds $t_{L}$ for development were estimated from the linear regression (STATA software) of developmental rates $(\mathrm{y}=1 /$ developmental time) on constant temperature [18].

\section{Results}

\subsection{Growth under Different Constant Temperature Regimes}

The mean minimum duration of development $( \pm$ S.D.) from oviposition to pupariation and from oviposition to eclosion (total immature development) at each of the six studied temperature regimes is given in Table 1.

\subsection{Developmental Threshold}

The rate of total immature development increased with temperature, with development rates of 0.0500 , $0.0588,0.0667,0.0800$, and 0.0909 , at 20, 22, 24, 26 and $28{ }^{\circ} \mathrm{C}$, respectively, and $\mathrm{R}^{2} 0.9908$;

$\mathrm{y}=0.0051 \mathrm{x}-0.0543$. From the regression line plotted in Fig. 10, it was calculated that the minimum development threshold $\left(t_{L}\right)$ for total immature development was $10.6{ }^{\circ} \mathrm{C}$.

3.3 Temperature Summation Model for the Six Landmarks within the Pupal Stage

In the authors' experiments, development of $L$. sericata was linearly related to temperature $\left(\mathrm{R}^{2}=0.99\right.$, $P<0.01)$ between $20{ }^{\circ} \mathrm{C}$ and $28{ }^{\circ} \mathrm{C}$. The threshold temperature $\left(10.6{ }^{\circ} \mathrm{C}\right)$ was roughly calculated. This information has allowed the calculation of the ADD for each landmark within the pupal stage (Table 2).

\section{Discussion}

In this experiment, Lucilia sericata development was linear between $20{ }^{\circ} \mathrm{C}$ and $28^{\circ} \mathrm{C}$. Average LDT was $10.6{ }^{\circ} \mathrm{C}$ and average ADD was 193 . This value is

Table 1 Minimum developmental times of Lucilia sericata life stages at six constant temperature regimes. The values are expressed as mean days \pm S.D. $(n=3)$.

\begin{tabular}{lll}
\hline \multirow{2}{*}{$\mathrm{T}\left({ }^{\circ} \mathrm{C}\right)$} & \multicolumn{2}{c}{ Days from oviposition to } \\
\cline { 2 - 3 } & Puparation & Eclosion \\
\hline 20 & $8 \pm 0.5$ & $20 \pm 1.2$ \\
22 & $8 \pm 0.5$ & $17 \pm 1$ \\
24 & $6 \pm 1$ & $15 \pm 0.3$ \\
26 & $5 \pm 1$ & $12.5 \pm 0.5$ \\
28 & $5 \pm 0.4$ & $11 \pm 0.0$ \\
\hline
\end{tabular}




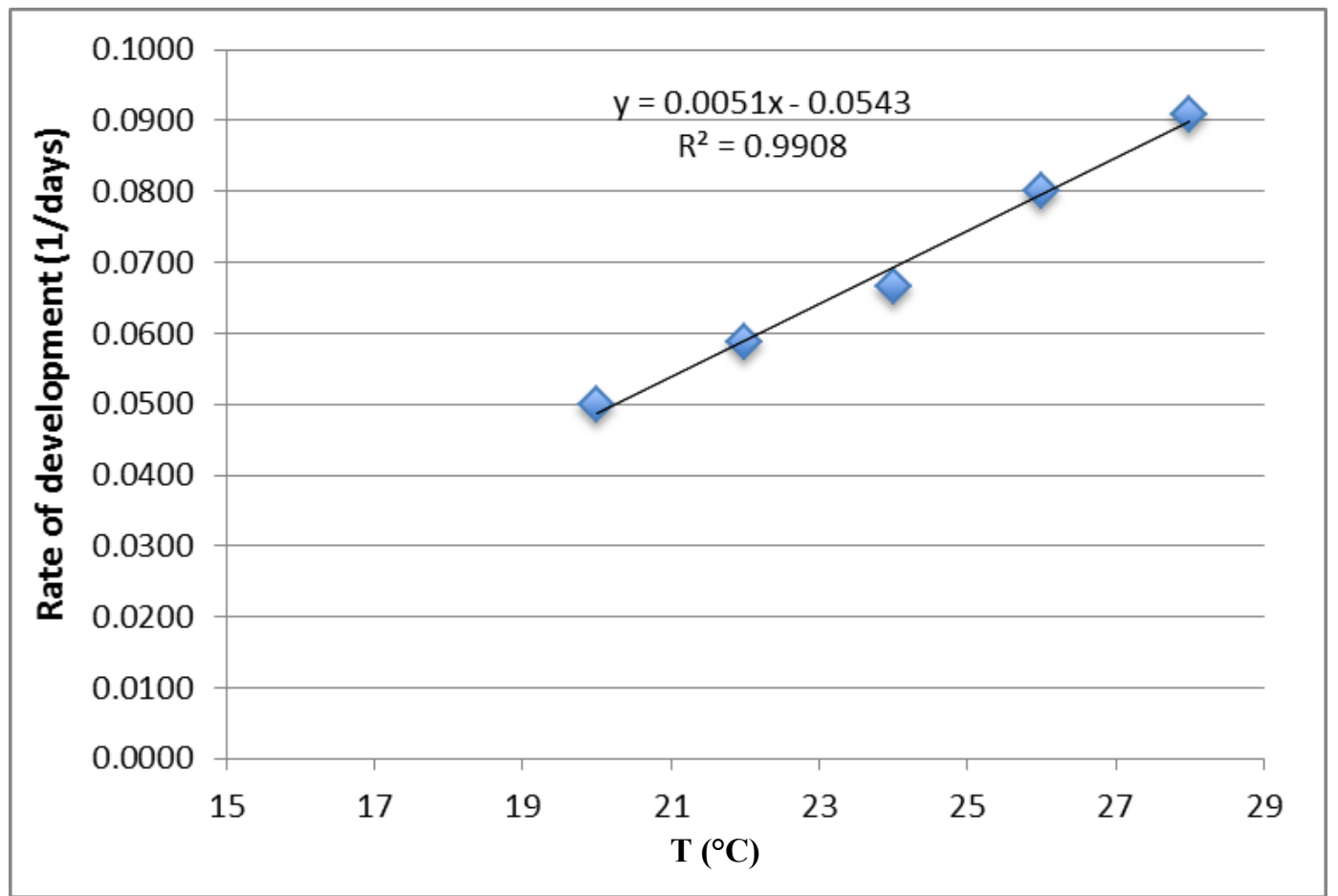

Fig. 10 Linear regression of rearing temperature and rate of development from oviposition to eclosion of Lucilia sericata.

Table 2 ADD of Lucilia sericata pupal landmarks at five constant temperature regimes. The values are expressed as mean ADD \pm S.D. $(n=3)$ and calculated using $t_{L}=10.6^{\circ} \mathrm{C}$. S1, Cryptocephalic pupa; S2, Phanerocephalic pupa; S3, Pharate adult; S4, Yellow eye; S5, Tanned chaetae; S6, Tanned legs; S7, adult stage.

\begin{tabular}{llllllll}
\hline $\boldsymbol{T}\left({ }^{\circ} \boldsymbol{C}\right)$ & $\boldsymbol{S 1}$ & $\boldsymbol{S 2}$ & $\boldsymbol{S 3}$ & $\boldsymbol{S 4}$ & $\boldsymbol{S 5}$ & $\boldsymbol{S 6}$ & $\boldsymbol{S} 7$ \\
$\mathbf{2 0}$ & $75.2 \pm 4.7$ & $94.0 \pm 9.4$ & $103.4 \pm 18.8$ & $141.0 \pm 11.4$ & $169.2 \pm 4.7$ & $178.6 \pm 0.0$ & $188.0 \pm 11.2$ \\
$\mathbf{2 2}$ & $91.2 \pm 5.7$ & $96.9 \pm 11.4$ & $102.6 \pm 11.4$ & $159.6 \pm 17.1$ & $171.0 \pm 0.0$ & $182.4 \pm 5.7$ & $193.8 \pm 11.4$ \\
$\mathbf{2 4}$ & $80.4 \pm 13.4$ & $100.5 \pm 6.7$ & $107.2 \pm 6.7$ & $147.4 \pm 13.4$ & $160.8 \pm 10.7$ & $174.2 \pm 0.0$ & $201.0 \pm 4.02$ \\
$\mathbf{2 6}$ & $77.0 \pm 15.4$ & $92.4 \pm 7.7$ & $107.8 \pm 15.4$ & $146.3 \pm 9.2$ & $161.7 \pm 7.7$ & $169.4 \pm 0.0$ & $192.5 \pm 7.7$ \\
$\mathbf{2 8}$ & $87.0 \pm 7.0$ & $95.7 \pm 5.2$ & $104.4 \pm 0.0$ & $147.9 \pm 0.0$ & $165.3 \pm 5.0$ & $174.0 \pm 5.2$ & $191.4 \pm 0.0$ \\
\hline
\end{tabular}

not similar to Marchenko results (LDT $9{ }^{\circ} \mathrm{C}$ and ADD 207) [19]. This discrepancy could be attributed to variation in experimental method (extrinsic factors), but equally to geographic adaptation (intrinsic factors) could be used to explain the difference in the temperature-dependent development observed [16].

During the development of pupae, it was observed that within the body divisions there is an antero-posterior sequence. Abdominal bristles tan later than those on the head and thorax; and even among the abdominal segments the bristles on the anterior segments tan earlier than those on the posterior segments. On the legs the sequence is proximo-distal and to bristles on the tarsi are the last to tan. Similar sequential tanning in the leg bristles has been noted in Drosophila by Brainridge and Bownes [20]. These observations were used to define the six developmental pupal stages described and to calculate a thermal summation for each of the stages.

The development of these morphological features and functions in pupae is not linear [21]. Indeed the range of ADD values in the different pupal phases varies widely. Finell and Jarvilehto [21] reported that after pupation there follows a long hystolitic period and then histogenesis begins, at first slowly and then at an increasing rate. Hence, the first periods are longer than the later ones and the period from S1 to S4 (as described by Finel juvenile pupal phases) lasts 
relatively longer that from S4 to S6 ( mature pupal phases) [16]. The variability of ADD of each landmark at each temperature is coherent with than expected. Critical landmarks, where the authors found major variability are S1 (Cryptocephalic pupa) and S4 (Yellow eyed). S1 is a critical landmark because it is a first pupal phase. In this first phase, puparium elimination is very difficult. Also S4 is a critical phase because it shows a lot of variability. Probably, this variability is explicable by the short duration of the phase.

The calculation of the ADD value relating to the pupal stage and its landmarks for forensically important Diptera can be a useful methodological approach in the estimation of post-mortem interval, especially in the cases where adults and larval stages are absent and only puparia is available.

\section{Conclusions}

The pupal stage represents about $50 \%$ of the immature development time and the pupal age may therefore serve as an important tool in entomological PMI estimation. The data and pictures of developmental processes of $L$. sericata pupae at different constant temperatures presented in this paper will be helpful in future forensic investigations and will hopefully serve as a stimulus to similar studies elsewhere.

Even if this must be considered as a preliminary study, some critical issues, which must be fixed in further experiments, have emerged:

ADD data did not take account of any drop in temperature experienced by the pupae, which have buried themselves, but relate most appropriately to those exposed to ambient temperature.

Larvae were fed with an atypical food substrate. Food substrate plays an important role in the overall development rate of Calliphoridae larvae. For this reason in the future we need to and must provide an artificial larval diet [22, 23]. A proper standardized artificial diet, with the appropriate amount of protein, vitamin and cholesterol, can ensure the success of rearing for several generations with a low decrease in viability.

Therefore it would be necessary to create a suitable protocol for the observation of pupal characters to make more efficacious the methodological approach mentioned above.

\section{References}

[1] Hall, R. D. 1990. "Medicocriminal Entomology." In: Entomology and Death: A Procedural Guide, edited by Catts, E. P., and Haskell, N. H. Clemson, SC: Joyce's Print Shop.

[2] Wall, R., and Warnes, M. L. 1994. "Responses of the Sheep Blowfly Lucilia sericata to Carrion Odour and Carbon Dioxide." Entomol Exp. Appl. 73: 239-46.

[3] Fisher, P., Wall, R., and Ashworth, J. R. 1998. "Attraction of the Sheep Blowfly, Lucilia sericata (Diptera: Calliphoridae) to Carrion Bait in the Field." Bull Entomol Res. 88: 611-6.

[4] Anderson, G. S. 2001. "Succession on Carrion and Its Relationship to Determining Time of Death." In: Forensic Entomology: The Utility of Arthropods in Legal Investigations, edited by Byrd, J. H., and Castner, J. L. Boca Raton, FL: CRC Press, 143-75.

[5] Braack, L. 1981. "Visitation Patterns of Principal Species of the Insect Complex at Carcasses in the Kruger National Park." Koedoe 24: 33-49.

[6] Erzinclioglu, Y. Z. 1996. Blowflies, edited by Slough, U. K. Richmond Publishing.

[7] Lane, R. P. 1975. "An Investigation into Blowfly (Diptera Calliphoridae) Succession on Corpses." J. Nat. Hist. 9: 581-8.

[8] Ames, C., and Turner, B. 2003. "Low Temperature Episodes in Development of Blowflies: Implications for Postmortem Interval Estimation." Med. Vet. Entomol. 17: 178-86.

[9] Sharpe, P. J. H., and DeMichele, D. W. 1977. "Reaction Kinetics of Poikilotherm Development." J. Theor. Biol. 64: 649-70.

[10] Byrd, J. H., and Allen, J. C. 2001. "Computer Modeling of Insect Growth and Its Application to Forensic Entomology." In: Forensic Entomology: The Utility of Arthropods in Legal Investigations, edited by Byrd, J. H. Boca Raton, FL: CRC Press.

[11] Higley, L. G., and Haskell, N. H. 2001. "Insect Development and Forensic Entomology." In: Forensic Entomology: The Utility of Arthropods in Legal Investigations, edited by Byrd, J. H., and Castner, J. L. Boca Raton, FL: CRC Press. 
[12] Greenberg, B., and Kunich, J. C. 2002. Entomology and the Law: Flies as Forensic Indicators. Cambridge, UK: Cambridge University Press.

[13] Sivasubramanian, P., and Biagi, M. 1983. "Scientific Note, Morphology of the Pupal Stages of the Flesh-Fly, Sarcophaga bullata (Parker) (Diptera: Calliphoridae)." Int. J. Insect Morphol Embryol 12 (5/6): 355-9.

[14] Smith, K. G. V. 1986. A Manual of Forensic Entomology. London, UK: Cornell University Press.

[15] Richards, C. S., Crous, K. L., and Villet, M. H. 2009. "Model of Development for Blowfly Sister Species Chrysomya chloropyga and Chrysomya putoria." Med. Vet. Entomol. 23: 56-61.

[16] Defilippo, F., Bonilauri, P., and Dottori, M. 2013. "Effect of Temperature on Six Different Developmental Landmarks within the Pupal Stage of the Forensically Important Blowfly Calliphora vicina (Robineau-Desvoidy) (Diptera: Calliphoridae).” $J$. Forensic Sci. 58: 1554-7.

[17] Feng, D. X., and Liu, G. C. 2013. "Pupal Age Estimation of Forensically Important Megaselia spiracularis Schmitz (Diptera: Phoridae)." Forensic science international 231: 199-203.
[18] Campbell, A., Frazer, B. D., Gilbert, N., Gutierrez, A. P., and MacKauer, M. 1947. "Temperature Requirements of Some Aphids and Their Parasites." J. Appl. Ecol. 11: 431-8.

[19] Marchenko, M. I. 2001. "Medico-Legal Relevance of Cadaver Entomofauna for the Determination of the Time since Death." Forensic Sci. Int. 120: 89-109.

[20] Brainridge, S. P., and Bownes, M. 1981. "Staging the Metamorphosis of Drosophila melanogaster." J. Embryol Exp. Morphol 66: 57-80.

[21] Finell, N., and Jarvilehto, M. 1983. "Development of the Compound Eyes of the Blowfly Calliphora erythrocephala: Changes in Morphology and Function during Metamorphosis.” Ann. Zool. Fenn. 20: 223-34.

[22] Richards, C. S., Rowlinson, C. C., Cuttiford, L., Grimsley, R., and Hall, M. J. R. 2013. "Decomposed Liver Has Significantly Adverse Affect on the Development Rate of Blowfly Calliphora vicina." Int J. Legal Med. 127: 259-62.

[23] Chaudhury, M. F. 2009. "Insect Nutrition, Feeding, and Artificial Diets." In: Principles and Procedures for Rearing High Quality Insects, edited by Schneider, J. C. Mississippi State University. 